\title{
Arcabouço geológico e hidrofácies do Sistema Aquífero Guarani, no município de Ribeirão Preto (SP)
}

\author{
Flavio de Paula e Silva ${ }^{1}$, Chang Hung Kiang ${ }^{2}$, Maria Rita Caetano-Chang ${ }^{3}$ \& Osmar Sinelli ${ }^{4}$
}

\begin{abstract}
Resumo Estudos geológicos e hidrogeológicos de subsuperfície, realizados com perfis geofísicos de poços profundos, permitiram delinear o arcabouço geológico e caracterizar as várias hidrofácies do Sistema Aqüífero Guarani (SAG), no município de Ribeirão Preto. O SAG, materializado pelas formações Pirambóia e Botucatu, assenta-se sobre substrato praticamente impermeável, constituído por rochas pelíticas da Formação Corumbataí, cujo comportamento hidrodinâmico regional é de um aqüiclude; na maior parte da área, o SAG está recoberto por vulcânicas básicas da Formação Serra Geral. As formações Pirambóia e Botucatu exibem padrões geofísicos característicos que permitem excelente correlação entre poços, e suas variações faciológicas atestam a complexidade estratigráfica do SAG. Somente um dos poços estudados atravessou toda seqüência mesozóica, razão pela qual não foi possível a análise de variabilidade da espessura da Formação Pirambóia. No caso da Formação Botucatu, a preservação do relevo de dunas pelas lavas e as depressões resultantes de erosão eólica pronunciada são responsáveis pelas variações de espessura. Tal situação evidencia a inadequabilidade de utilização do contato entre as formações Botucatu e Serra Geral como datum para análises estruturais. A configuração do mapa de contorno estrutural da discordância existente no topo da Formação Pirambóia, considerada um bom marco local, confirmou a existência de área estruturalmente rebaixada na porção centro-sudoeste do município. Esta depressão, denominada Depressão de Ribeirão Preto em trabalhos anteriores, apresenta caimento para sudoeste e desnível de mais de 100 metros em cerca de $15 \mathrm{~km}$. Três hidrofácies - A (inferior), B (mediana) e C (superior) - foram identificadas no Aqüífero Pirambóia, sendo que a superior e a inferior apresentam características, em perfis, indicativas de permeabilidade reduzida, enquanto a intermediária apresenta características de elevada permoporosidade. O Aqüífero Botucatu comporta uma única hidrofácies (D), com características indicativas de elevada permoporosidade em perfis.
\end{abstract}

Palavras-chave: Sistema Aqüífero Guarani, Bacia do Paraná, perfis geofísicos.

\begin{abstract}
Geologic Framework and Hydrofacies of Guarani Aquifer System in the City of Ribeirão Preto $(S P)$. Subsurface geology and hydrogeological studies using geophysical well logs allowed to define the geologic framework and to characterize the hydrofacies of Guarani Aquifer System (GAS) in the city of Ribeirão Preto. The GAS is composed by the sediments of Pirambóia and Botucatu formations and rests upon an impermeable pelitic substrate, the Corumbatai Formation, which is considered an aquiclude, and is mostly covered by basic volcanic rocks of Serra Geral Formation. The typical geophysical patterns of Pirambóia and Botucatu formations are well correlated and their complex facies variations are compatible to the stratigraphy of the GAS. The thickness variations of the Pirambóia Formation were not defined because only one of the studied wells penetrated the entire Mesozoic sequence. In the case of Botucatu Formation the paleodune relief preserved by the volcanic lavas and the depressions created by deep aeolian erosion are responsible for the thickness variations. This situation emphasizes the inadequacy of using the Botucatu and Serra Geral formations contact as a datum for structural analysis. The shape of the structural contour of the unconformity at the top of Pirambóia Formation, that is considered to be a good local marker, confirmed the existence of a structural low in the central-southwestern portion of the city. The Ribeirão Preto depression plunges southwest dropping over 100m across $15 \mathrm{Km}$. Three hydrofacies - A (lower), B (medium) and C (upper) - were identified in the Pirambóia Aquifer. The upper and lower hydrofacies show log signature typical of reduced permeability, whereas the medium one shows log signature of high permeability. The Botucatu Aquifer has a single hydrofacies (D) with log signature indicative of elevated permeability.
\end{abstract}

Keywords: Guarani Aquifer System, Paraná Basin, well logs.

1- Laboratório de Estudos de Bacia - LEBAC, Departamento de Geologia Aplicada, Instituto de Geociências e Ciências Exatas, Universidade Estadual Paulista “Júlio de Mesquita Filho”, UNESP, Rio Claro (SP), Brasil. Email: flaviops@rc.unesp.br

2- Laboratório de Estudos de Bacia - LEBAC, Departamento de Geologia Aplicada, Instituto de Geociências e Ciências Exatas, UNESP, Rio Claro (SP), Brasil. Email: chang@rc.unesp.br

3- Laboratório de Estudos de Bacia - LEBAC, Departamento de Geologia Aplicada, Instituto de Geociências e Ciências Exatas, UNESP, Rio Claro (SP), Brasil. Email: mrchang@rc.unesp.br

4- Laboratório de Estudos de Bacia - LEBAC, Departamento de Geologia Aplicada, Instituto de Geociências e Ciências Exatas, UNESP, Rio Claro (SP), Brasil. Email: osmarsinelli@coc.com.br 
INTRODUÇÃOO O Sistema Aqüífero Guarani é considerado um dos maiores mananciais de água subterrânea do mundo. Localiza-se na região centro-leste da América do Sul e ocupa área de cerca de 1,2 milhão de $\mathrm{km}^{2}$, distribuída em quatro países: Brasil $\left(840.000 \mathrm{~km}^{2}\right)$, Argentina $\left(225.000 \mathrm{~km}^{2}\right)$, Paraguai $\left(71.700 \mathrm{~km}^{2}\right)$ e Uruguai $\left(58.500 \mathrm{~km}^{2}\right)$ (Araújo, 1995). No Brasil, abrange os estados de Goiás, Mato Grosso do Sul, Minas Gerais, Paraná, Santa Catarina, Rio Grande do Sul e São Paulo. Neste último, ocupa cerca de $60 \%$ de seu território $\left(155.800 \mathrm{~km}^{2}\right)$; comparece confinado por derrames de rochas basálticas em $90 \%$ de sua área de ocorrência, o que lhe confere condições de artesianismo em $80 \%$ da área (DAEE, 1990). No Estado de São Paulo, o arcabouço estratigráfico do Sistema Aqüífero Guarani (SAG) é constituído pelos arenitos triássicos da Formação Pirambóia, e juro-cretáceos da Formação Botucatu.

Na cidade de Ribeirão Preto, localizada na porção nordeste do Estado de São Paulo, distante cerca de $320 \mathrm{~km}$ da capital São Paulo, com população de mais de 500.000 habitantes distribuída em área urbana de $274 \mathrm{~km}^{2}$ e com atividade econômica pujante, o SAG destaca-se por ser o único manancial utilizado para realizar o abastecimento público de água (Fig. 1). A produção, que era de $4.000 \mathrm{~m}^{3} / \mathrm{h}$ no início da década de 1970 (Sinelli, 1971a), atualmente alcança cerca de 13.400 $\mathrm{m}^{3} / \mathrm{h}$, procedente de 99 poços públicos. Este volume representa quase 98 milhões de metros cúbicos anuais extraídos desse manancial subterrâneo, sem considerar o volume retirado por poços particulares legais e clandestinos (DAERP, 2007).

$\mathrm{O}$ elevado volume de água retirado do SAG tem ocasionado problemas de rebaixamento do nível potenciométrico devido a interferências entre poços. Utilizando registros de poços, Sinelli (1984) delineou vários cenários de evolução do rebaixamento do nível estático do aqüífero em Ribeirão Preto, desde o ano de 1920. O autor constatou a falta de planejamento na locação de poços públicos, concluindo que o incremento dos processos de interferência poderiam comprometer as reservas permanentes do aqǘf́ero.

Os estudos hidrogeológicos pioneiros na região de Ribeirão Preto, sobre o então denominado Aqüífero Botucatu, atualmente consignado Sistema Aqüífero Guarani, tiveram início na década de 70 com os artigos publicados por Sinelli (1970, 1971a, b). Estes trabalhos esboçaram um primeiro painel sobre as condições hidrogeológicas e tectônicas na área deste município, chamando atenção para a depressão topográfica aí existente. Para o autor, esta feição teria se originado por ação de tectônica rígida, responsável pelo abatimento do topo do arenito Botucatu na porção central da cidade, conjetura corroborada por Soares et al. (1973) e Soares (1974).

Com intuito de conhecer o potencial de recursos hídricos do Estado de São Paulo, o Departamento

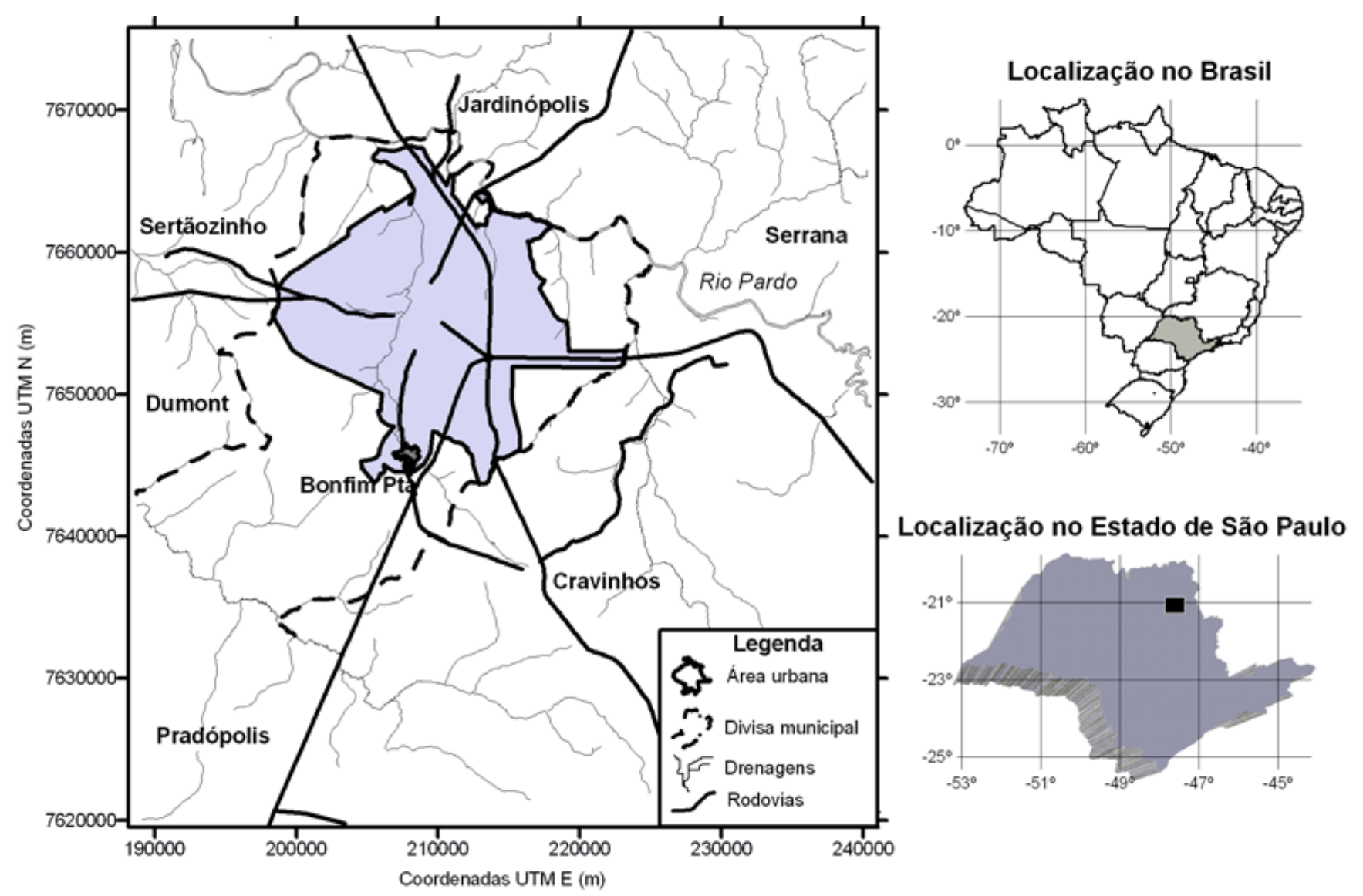

Figura 1 - Mapa de localização do município de Ribeirão Preto, com delimitação da área urbana. 
de Águas e Energia Elétrica (DAEE) promoveu, em meados da década de 70, estudo sobre águas subterrâneas da Região Administrativa ${ }^{0} 6$ (Ribeirão Preto) (DAEE, 1974), enfatizando que, apesar das diferenças litológicas entre as formações Pirambóia e Botucatu, não era possível, com os dados disponíveis, estabelecer uma diferenciação no sistema de fluxo.

Com o objetivo de estabelecer a geometria e as características hidráulicas do "Aqüífero Botucatu" na área de Ribeirão Preto, Davino et al. (1980) utilizaram vários métodos geofísicos e concluíram pela necessidade desse conhecimento como base para utilização racional dessas reservas subterrâneas.

Em trabalho de síntese hidrogeológica, Sinelli et al. (1980) reiteraram o comportamento heterogêneo do aqüífero em Ribeirão Preto, que seria decorrente de causas tectônicas e de notável incidência de intrusões magmáticas. Estendendo os estudos para a Bacia do Rio Pardo, Sinelli et al. (1984) verificaram a existência de grande número de rochas intrusivas, em forma de soleiras e lacólitos, secionando o arcabouço do "Aqüífero Botucatu". Segundo esses autores, as intrusões substituem parte da espessura saturada, alterando os parâmetros hidrodinâmicos do aqüífero e causando dificuldades às avaliações geológica e hidrogeológica.

Ainda que os estudos hidrogeológicos anteriores tenham acumulado acervo extraordinário de dados geológicos e geofísicos de subsuperfície, muitas questões técnicas não foram resolvidas por absoluta carência de dados de qualidade. A precariedade das informações extraídas de relatórios de perfuração de poços sempre se constituiu em obstáculo à identificação e à delimitação das diversas zonas hidroestratigráficas, dificultando sua correlação com as características litoestratigráficas e estruturais das unidades rochosas, bem como a avaliação de seu potencial hídrico.

Os estudos hidrogeológicos de subsuperfície constituem instrumento essencial na gestão dos recursos hídricos subterrâneos. Amparados pela utilização de perfis geofísicos calibrados (radioativos, elétricos e acústicos), obtidos de perfurações efetuadas para extração de água subterrânea, estes estudos permitem identificar e correlacionar as distintas unidades aqüíferas, determinar os intervalos mais produtivos, estimar as reservas hídricas estáticas e delinear as condições estruturais que afetam os reservatórios subterrâneos. Desse modo, podem discriminar o arcabouço hidrogeológico em porções mais permeáveis (aqüíferos) ou menos permeáveis (aqüitardos), e auxiliar no entendimento do comportamento do sistema de fluxo regional.

Utilizando dados de poços profundos e respectivas perfilagens geofísicas, é aqui apresentado o arcabouço geológico do SAG, na área urbana de Ribeirão Preto, bem como as principais características das hidrofácies que o compõem.

CONTEXTO GEOLÓGICO O arcabouço litoestratigráfico do Sistema Aqüífero Guarani, no Estado de São Paulo, é constituído pelas formações Pirambóia e Botucatu que, juntamente com os derrames basálticos da Formação Serra Geral, integram uma seqüência vulcanoclástica continental, reunida no Grupo São Bento (Bacia do Paraná), com idade situada entre o Eotriássico e o Eocretáceo. Esta seqüência é limitada, na base e no topo, por discordâncias regionais que separam, respectivamente, rochas paleozóicas e neocretáceas. A Formação Pirambóia, situada em posição estratigráfica inferior, insere-se na Superseqüência Gondwana II, enquanto a Formação Botucatu, superior, insere-se na Superseqüência Gondwana III, juntamente com os magmatitos Serra Geral que a recobrem, de acordo com Milani (1997). Essas superseqüências correspondem às seqüências Triássica e Juro-Cretácea, respectivamente, de Zalán et al. (1987). A figura 2 apresenta a coluna estratigráfica parcial representativa da área de Ribeirão Preto.

Formação Pirambóia A Formação Pirambóia foi formalmente definida por Soares $(1973,1975)$, que a descreveu como constituída por um membro inferior, mais argiloso, composto de arenitos finos intercalados por freqüentes camadas de argilito e de folhelhos arenosos e sílticos, com estratificação plano-paralela, e por um membro superior, composto de bancos de arenitos pouco a muito argilosos, com estratificação cruzada planar tangencial, de pequeno e médio portes, sucedidos por bancos de arenitos muito argilosos com estratificação plano-paralela, lamitos e argilitos, em repetição cíclica.

Originalmente com deposição atribuída a ambiente fluvial meandrante psamítico por Soares (1973), a Formação Pirambóia teve sua gênese revista por Caetano-Chang (1997), que demonstrou a predominância da deposição eólica sobre a deposição fluvial, francamente subordinada, na região centro-leste paulista. A unidade, essencialmente arenosa, foi depositada em ambiente desértico com meta-saturação em areias, onde se intercalam fácies de dunas com foresets de pequeno a grande portes, em arenitos geralmente finos, regular

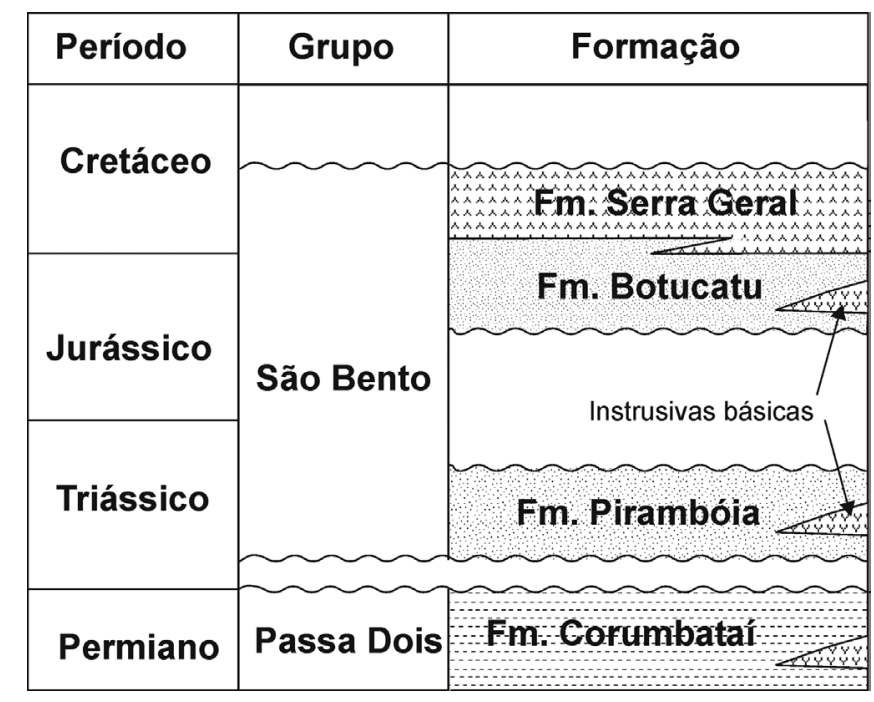

Figura 2 - Coluna estratigráfica parcial da área de Ribeirão Preto. 
a bem selecionados; fácies de interdunas úmidas, predominantes, compostas por arenitos siltosos com estruturas preservadas de ôndulas eólicas e bioturbações; fácies de interdunas secas e lençóis de areia, mais freqüentes nas porções média e superior da unidade; fácies de interdunas aquáticas ou de overbank, em geral compostas por lamitos arenosos, mais freqüentes na porção inferior da formação, onde se associam a fácies fluviais de rios temporários.

Estudos hidrogeológicos realizados em Bauru (SP) por Paula e Silva (1988) e Paula e Silva \& Cavaguti (1994) assinalam a ocorrência de arenitos grossos a conglomeráticos, com espessura de cerca de 20 a 30 metros, na porção mediana da Formação Pirambóia, cujas características de permoporosidade seriam responsáveis pela elevada produtividade de poços que atravessam esse pacote. Assine (1993) destacou a ocorrência de arenitos conglomeráticos de origem fluvial, na parte superior da unidade, na região de São Pedro (SP). Caetano-Chang (1997) e Caetano-Chang \& Wu $(1993,2006)$ descreveram arenitos conglomeráticos e conglomerados de sistema fluvial entrelaçado, intercalados a arenitos finos a grossos, eólicos, compondo uma sucessão que atinge cerca de 45 metros de espessura, pertencente à porção superior da Formação Pirambóia, no centro-leste paulista. Esta fácies foi denominada Arenitos Itirapina por Caetano-Chang \& $\mathrm{Wu}$ (2006).

Para Schneider (1974), a Formação Pirambóia apresenta espessura máxima, em superfície, de 270 metros na região de Anhembi (SP) e São Pedro (SP), e de 350 metros, em subsuperfície, no poço TQ-1-MT (MT); Soares (1975) apontou espessura máxima de 300 metros na bacia do Rio Tietê, enquanto Sinelli (1980) anotou espessura máxima de 140 metros, na região de Ribeirão Preto.

No Estado de São Paulo, a Formação Pirambóia assenta-se em contato discordante erosivo sobre formações permianas da Bacia do Paraná (Teresina, Corumbataí e Rio do Rasto), conforme aceito pela maioria dos pesquisadores (Soares, 1973, 1975, 1981; Zalán et al., 1987; Milani et al., 1994; Caetano-Chang, 1997).

Formação Botucatu A Formação Botucatu foi definida formalmente por Soares $(1973,1975)$, sendo constituída predominantemente por arenitos finos a médios, exibindo estratificações cruzadas de grande e médio portes, depositados por processos eólicos em ambiente desértico. Na unidade predominam fácies de foresets de dunas eólicas, de interdunas secas e de lençóis de areia (Caetano-Chang, 1997).

A espessura desta unidade, segundo Soares (1975), é bastante variável, porém inferior a 150 metros. Para Sinelli (1980), a espessura da Formação Botucatu não ultrapassa 80 metros na região de Ribeirão Preto. Almeida (1953) assinalou que, em alguns casos, os derrames basálticos recobriram campos de dunas concordantemente, preservando a forma original das construções eólicas. Para Assine et al. (2004), a variação de espessura da Formação Botucatu é, em grande parte, função da distribuição dos campos de dunas e de seu recobrimento pelos derrames basálticos da Formação Serra Geral.

O contato basal com a Formação Pirambóia representa uma discordância regional, segundo grande parte dos autores (Zalán et al.,1987; Milani, 1994, 1997; Caetano-Chang, 1997).

Formação Serra Geral A Formação Serra Geral compreende o conjunto de derrames de rochas basálticas e de magmatitos intrusivos associados, com cerca de 2000 metros de espessura máxima na região sudoeste do Estado de São Paulo, atestada por perfurações de poços de petróleo e de água subterrânea. De maneira generalizada, os termos petrológicos da Formação Serra Geral são dominados por basaltos toleíticos e andesitos basálticos, ocorrendo quantidades subordinadas de riolitos e riodacitos (Peate et al., 1992).

O contato basal com a Formação Botucatu, localmente abrupto, mostra regionalmente relações de interdigitamento entre os primeiros derrames basálticos e os arenitos eólicos desta unidade. Para Soares (1973), a continuidade do processo eólico durante as primeiras manifestações vulcânicas deu origem a numerosos corpos arenosos intertrapeanos, com espessura de até 40 metros. No entanto, Soares (1975) reconheceu que é difícil precisar se os magmatitos, aos quais se intercalam corpos arenosos, são intrusivos ou extrusivos. Assim, este contato é geralmente colocado na base do primeiro derrame basáltico.

A recorrência de arenitos nas camadas inferiores dos basaltos da Formação Serra Geral assinala a contemporaneidade entre a sedimentação eólica e os primeiros derrames de lavas.

Aspectos Tectônico-Estruturais No Mesotriássico, esforços compressionais decorrentes de evento orogênico na margem sul do Gondwana deram origem a movimentações positivas em alguns setores da Bacia do Paraná, propiciando a formação de uma superfície erosional, sobre a qual se depositaram as unidades neotriássicas (Milani, 1994). A deposição das formações Pirambóia e Botucatu, culminando com o extravasamento de lavas basálticas da Formação Serra Geral, no Eocretáceo, foi fortemente influenciada pela ruptura do Gondwana $\mathrm{e}$ pela abertura do Atlântico Sul (Zalán et al., 1987).

Os primeiros pulsos positivos do Arco de Ponta Grossa, relacionados à ruptura gondwânica, podem ter sido responsáveis pelos depósitos arenosos da Formação Pirambóia e, posteriormente, pela discordância entre as seqüências Triássica e Juro-Cretácea (Zalán et al., 1987).

A Reativação Wealdeniana, responsável pelo vulcanismo da Bacia do Paraná e das bacias costeiras de Santos e Campos, propiciou o desenvolvimento de grandes fraturas e falhas de distensão paralelas ao eixo do Arco de Ponta Grossa (NW), além de intrusões básicas e alcalinas. Associadas a este evento, são relatadas compartimentações regionais de natureza estrutural e estratigráfica das formações Pirambóia e Botucatu, res- 
ponsáveis por variações na superfície potenciométrica e nas características hidrodinâmicas do Sistema Aqüífero Guarani (Strugale et al., 2002; Machado \& Faccini, 2004). Suguio et al. (1977) mencionaram a existência de um grande horst na região de Bauru-Agudos (SP), que elevou a sucessão de lavas basálticas, posteriormente removidas por erosão. $\mathrm{Na}$ área urbana de Bauru (SP), os efeitos da reativação promoveram a remoção de espessura considerável dos sedimentos constituintes do SAG (Paula e Silva, 1988; Paula e Silva \& Cavaguti, 1994).

Estudos realizados por Sinelli (1970,1971a, b), Soares (1974), Davino et al. (1980) e Sinelli et al. (1980) concluíram pela existência de um baixo estrutural, originado por falhas dispostas em mosaico, as quais teriam secionado toda coluna sedimentar da bacia, na área de Ribeirão Preto. Nestes estudos, Sinelli (1971a) identificou falhas horizontais e normais; Soares et al. (1973), porém, reconheceram somente falhas de caráter normal e com rejeitos modestos, mas admitiram a existência de falhas sub-verticais de compensação, associadas às intrusões de diabásio.

MÉTODOS DE ESTUDO Os estudos de subsuperfície, ora realizados na área urbana de Ribeirão Preto, utilizaram dados extraídos de 97 poços perfurados para captação de água (Fig. 3). Destes, 32 apresentam perfis geofísicos calibrados - curvas de raios gama (RG) com calibração API (American Petroleum Institute), potencial espontâneo (SP), resistividade normal curta (SN), resistividade induzida (IL) e sônico compensado (BCS) - e 4 apresentam perfis convencionais - curvas de raios gama escala cps (counts per second), potencial espontâneo e resistência.

Os perfis calibrados prestam-se a análises quantitativas, enquanto os perfis convencionais podem ser utilizados somente para análises qualitativas. Os perfis geofísicos utilizados na pesquisa de água subterrânea registram propriedades elétricas, eletromagnéticas, radioativas e acústicas das rochas, que podem ser interpretadas em termos de porosidade, salinidade de águas intersticiais, conteúdo argiloso, tipo de fluido, etc. Não fornecem diretamente valores de condutividade hidráulica, mas permitem distinguir os intervalos com melhores características de permeabilidade.

A interpretação dos parâmetros registrados pelos perfis geofísicos conduz à identificação das litologias atravessadas pelo poço, da litoestratigrafia e das zonas de maior e de menor permeabilidade; como são

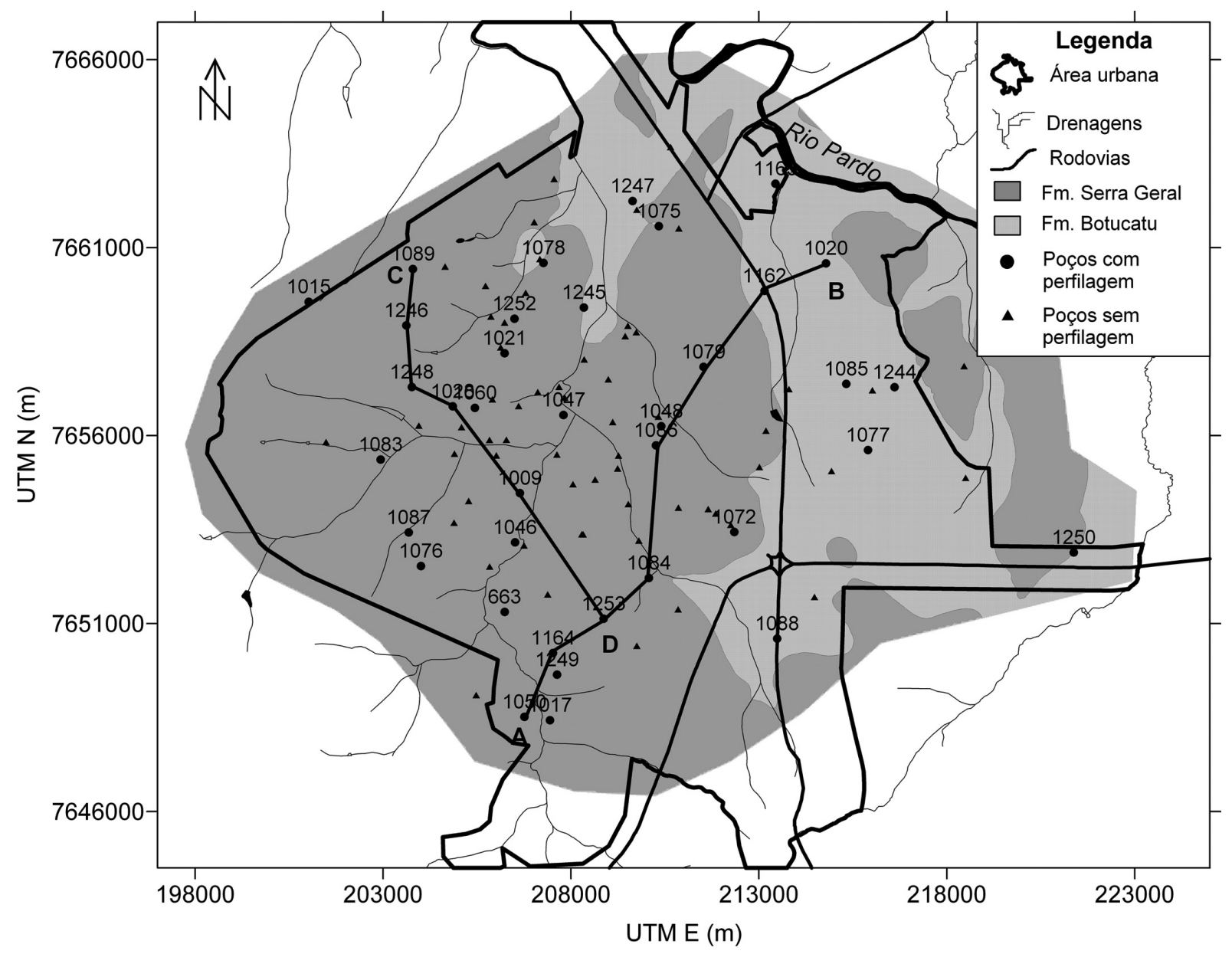

Figura 3 - Mapa geológico simplificado da área urbana de Ribeirão Preto (SP), com a localização dos poços utilizados neste estudo, e das seções geológicas $A-B$ e $C$-D, apresentadas nas figuras 4 e 5. 
corridos continuamente, do fundo do poço até a superfície, constituem instrumentos adequados ao estudo de sucessões sedimentares, em escala de metros a centenas de metros, podendo ser usados na análise da evolução paleoambiental.

Dados litoestratigráficos do contato entre as formações Botucatu e Serra Geral, extraídos de perfis geofísicos e combinados com dados topográficos, permitiram a elaboração do mapa geológico simplificado da figura 3. Este mapa foi elaborado efetuando-se a subtração entre os grids da superfície topográfica e do topo da Formação Botucatu, na área estudada. O primeiro grid foi preparado em base de dados de extensão DXF (Autocad), extraída de mapa planialtimétrico (IBGE, Folha de Ribeirão Preto, escala 1:50.000), convertida para arquivo XYZ e re-interpolada com auxílio do software Surfer 7.0. O segundo grid foi preparado com a interpolação de dados pontuais de poços que atingiram o topo da Formação Botucatu. O grid final foi obtido com a subtração entre estes dois grids e reproduz a espessura de basaltos na área estudada, como será mostrado oportunamente. Os setores onde a espessura resultou nula ou negativa no grid representam ausência de rochas basálticas, ou seja, delimitam áreas de exposição de sedimentos constituintes do SAG. Comparado com mapas geológicos elaborados com dados de superfície por outros pesquisadores, este mapa mostra boa correspondência com os limites de ocorrência das principais unidades estratigráficas aflorantes na área.
ARCABOUÇO GEOLÓGICO O arcabouço estratigráfico do Sistema Aqüífero Guarani, em Ribeirão Preto, é composto pelas formações Pirambóia e Botucatu. Este pacote rochoso assenta-se sobre substrato praticamente impermeável, constituído por rochas pelíticas da Formação Corumbataí, cujo comportamento hidrodinâmico regional é de um aqüiclude. O SAG é recoberto, na maior parte da área estudada, pelas vulcânicas básicas da Formação Serra Geral, ausentes apenas em parte da porção leste e norte da área urbana, onde deixam expostos sedimentos arenosos pertencentes à unidade Botucatu (Fig. 3).

Seções geológicas segundo as direções SW-NE e NW-SE, elaboradas com perfis geofísicos calibrados da área urbana de Ribeirão Preto (Figs. 4 e 5), permitem distinguir e correlacionar as duas unidades litoestratigráficas principais que constituem o SAG - formações Pirambóia e Botucatu.

A espessura máxima perfurada na Formação Pirambóia, na área estudada, foi de 250 metros no poço 1086, sem contudo atingir o topo da Formação Corumbataí, sotoposta. Já a espessura da Formação Botucatu é bastante variável (Figs. 4 e 5), como nas demais áreas de sua ocorrência na bacia. Em subsuperfície, a espessura mínima constatada foi de 49 metros nos poços 1050 e 1079 (Fig. 4), e a máxima de 122 metros no poço 1072 (Fig. 6). As diferenças de espessura observadas na Formação Botucatu se devem, em grande parte, à configuração da superfície das dunas e à erosão

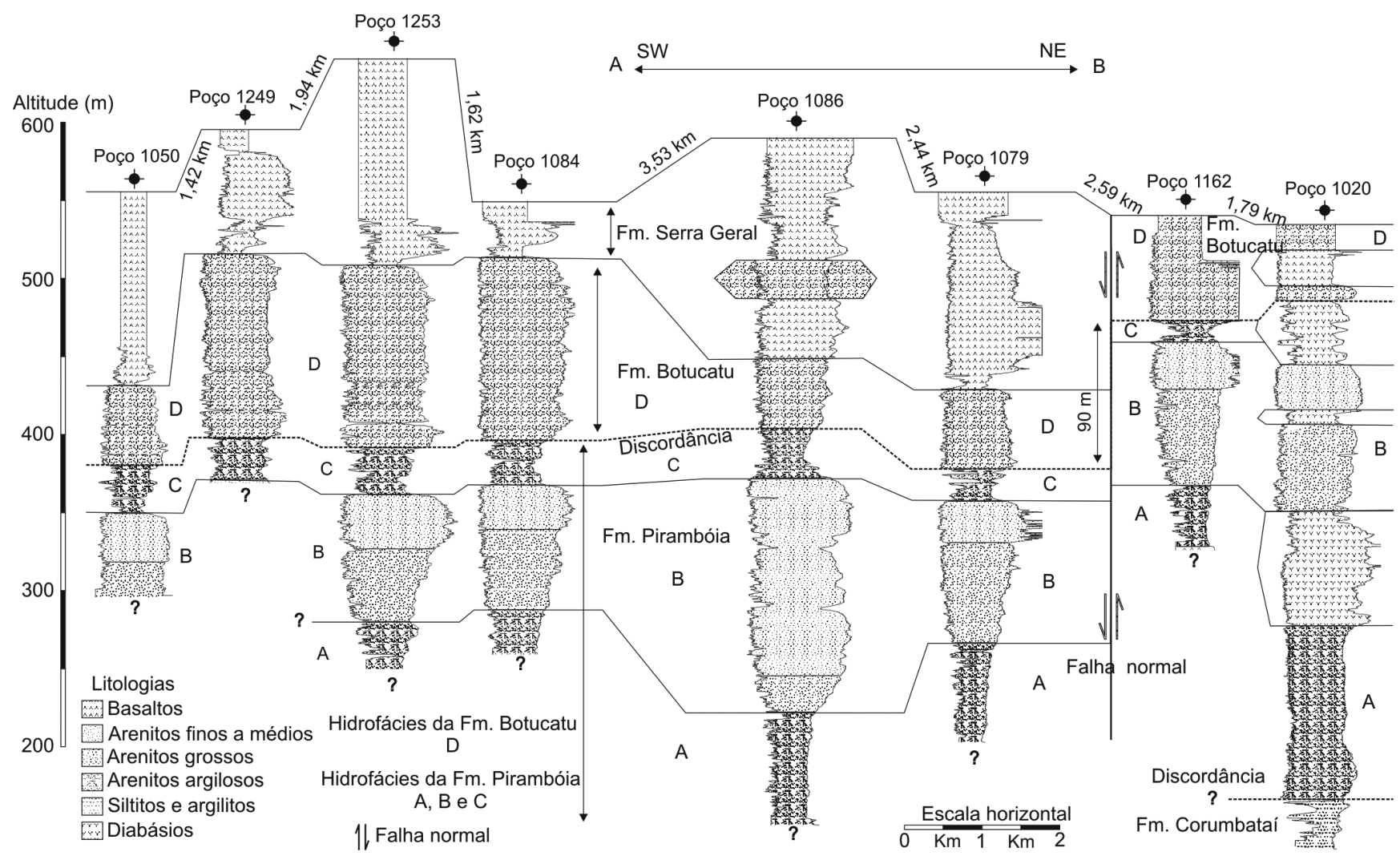

Figura 4 - Seção geológica A-B (sudoeste-nordeste). Localização na figura 3. 


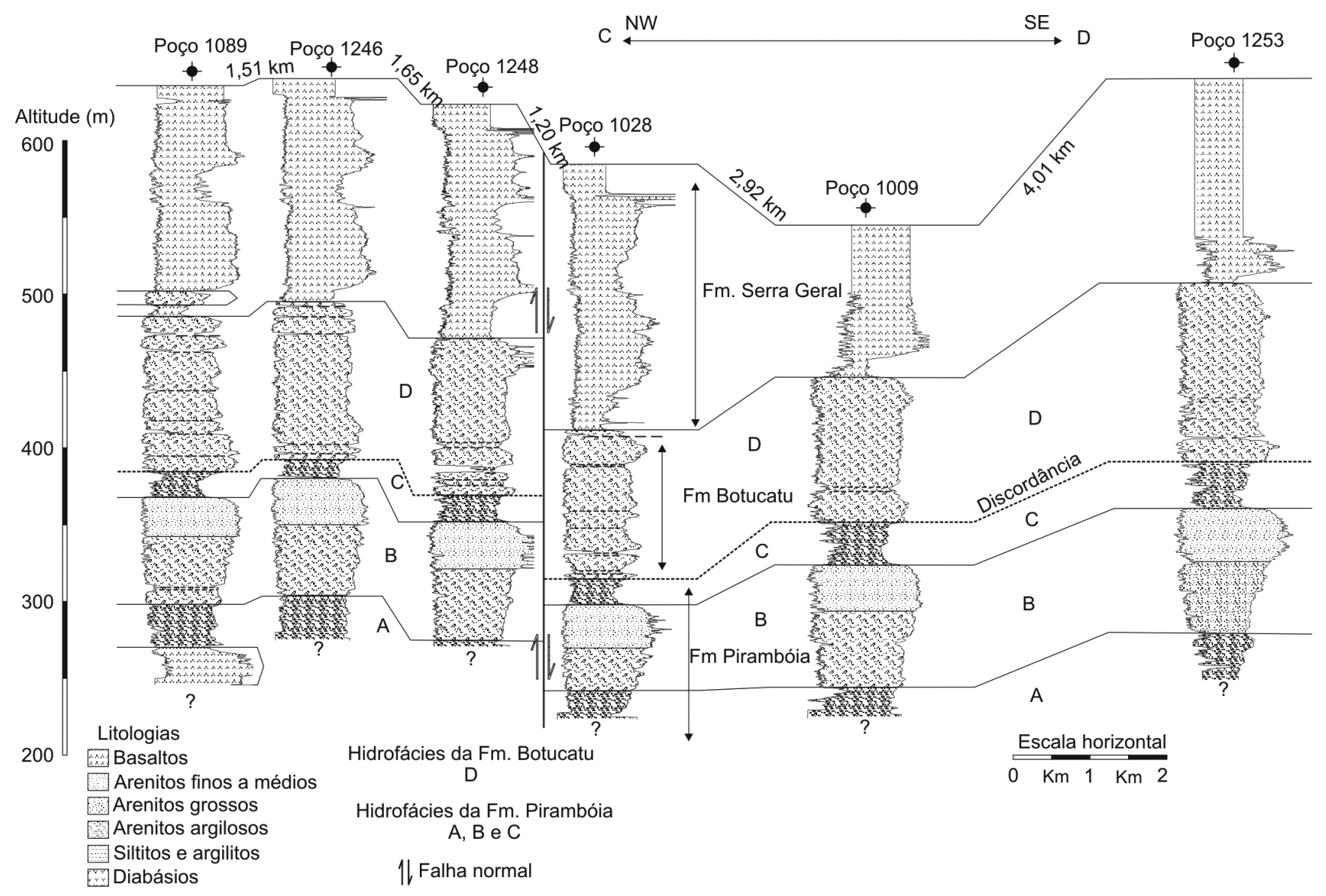

Figura 5 - Seção geológica C-D (noroeste-sudeste). Localização na figura 3.

eólica diferencial no ambiente desértico. O primeiro caso pode ser explicado pela conformação pretérita de superfícies de dunas, preservadas pelo recobrimento de lavas basálticas da Formação Serra Geral; no segundo caso, exemplificado pela correlação dos poços $1072 \mathrm{e}$ 1079 (Fig. 6), presume-se que determinadas áreas do ambiente desértico, particularmente áreas amplas de lençóis de areia e interdunas, tenham sofrido erosão mais pronunciada, com intensa remoção de material inconsistente pelo vento, formando grandes depressões posteriormente preenchidas por lavas basálticas.

O contato superior da Formação Botucatu é interdigitado com os derrames basálticos da Formação Serra Geral e, operacionalmente, pode ser demarcado abaixo do primeiro derrame, marco inicial da atividade vulcânica na bacia (Figs. 4 e 5). A maior parte dos magmatitos intercalados na porção superior da Formação Botucatu deve corresponder a rochas extrusivas, pelo que pode ser deduzido das correlações estratigráficas ensaiadas e pela inexistência de evidências distintivas de presença de rochas intrusivas, tanto concordantes como discordantes.

A figura 7 apresenta um perfil estratigráfico hipotético da sucessão mesozóica na cidade de Ribeirão Preto, elaborado com base em correlação de perfis geofísicos, em que a espessura máxima do SAG alcançaria 320 metros.
Quanto às variações de espessura de rochas vulcânicas que recobrem a Formação Botucatu e ao desnivelamento da cota do topo do SAG, questões estas ainda muito discutidas por diversos pesquisadores, a análise das seções geológicas das figuras 4 e 5 mostra que as causas dessas inconformidades devem-se à combinação de fatores atribuídos às contingências do ambiente deposicional, acima discutido, e à reorganização estrutural da bacia, em conseqüência do episódio termomagmático da Reativação Wealdeniana. No primeiro caso, as lavas basálticas se amoldaram ao paleo-relevo irregular formado pela superfície de topo da Formação Botucatu, preservando maiores espessuras nas porções de interdunas ou lençóis de areia do paleo-deserto; no segundo caso, movimentações verticais de blocos de amplitudes variáveis, concomitantes ao extravasamento de lavas, afetaram toda coluna sedimentar, propiciando o acúmulo de espessuras maiores em porções abatidas, similarmente ao observado na região de Bauru (SP) por Paula e Silva \& Cavaguti (1994).

A maior espessura preservada de basaltos, constatada em perfurações, foi de 195 metros no poço 1028 (Fig. 6). A figura 8 apresenta o mapa de espessura das lavas basálticas elaborado com a utilização de metodologia de subtração de grids, descrita anteriormente, podendo-se observar que as maiores espessuras tendem a situar-se a oeste e nos interflúvios das drenagens que 
cortam a área urbana de Ribeirão Preto. Ainda com relação ao desnivelamento da cota do topo do SAG, não se pode descartar a influência da tectônica cenozóica na estruturação final da seqüência mesozóica.

Apesar do grande número de poços perfurados na cidade de Ribeirão Preto, a maioria das informações estratigráficas geradas é incompleta e dificulta uma análise estrutural mais precisa, haja vista que apenas um único poço atravessou toda seqüência mesozóica (poço 1020) e atingiu a Formação Corumbataí (Fig. 4). O delineamento dessa superfície basal é essencial, pois fornece os elementos estruturais necessários para analisar a influência da tectônica no arcabouço do SAG. Por sua vez, o contato Botucatu/Serra Geral deve ser desconsiderado como datum para análises estruturais, em razão da irregularidade desta superfície e, conseqüentemente, de sua inadequabilidade como marco de referência. Alternativamente, ante a indisponibilidade deste horizonte específico, recorreu-se a outra superfície de referência (datum), resultante de ampla peneplanização, responsável pela extensa superfície de discordância que separa as formações Pirambóia e Botucatu. As figuras 4 e 5 mostram a perfeita correlação entre perfis geofísicos calibrados na área urbana de Ribeirão Preto e permitem distinguir tal discordância, que pode ser utilizada em estudos estruturais locais; esta superfície marca a passagem de arenitos argilosos, abaixo, com elevada
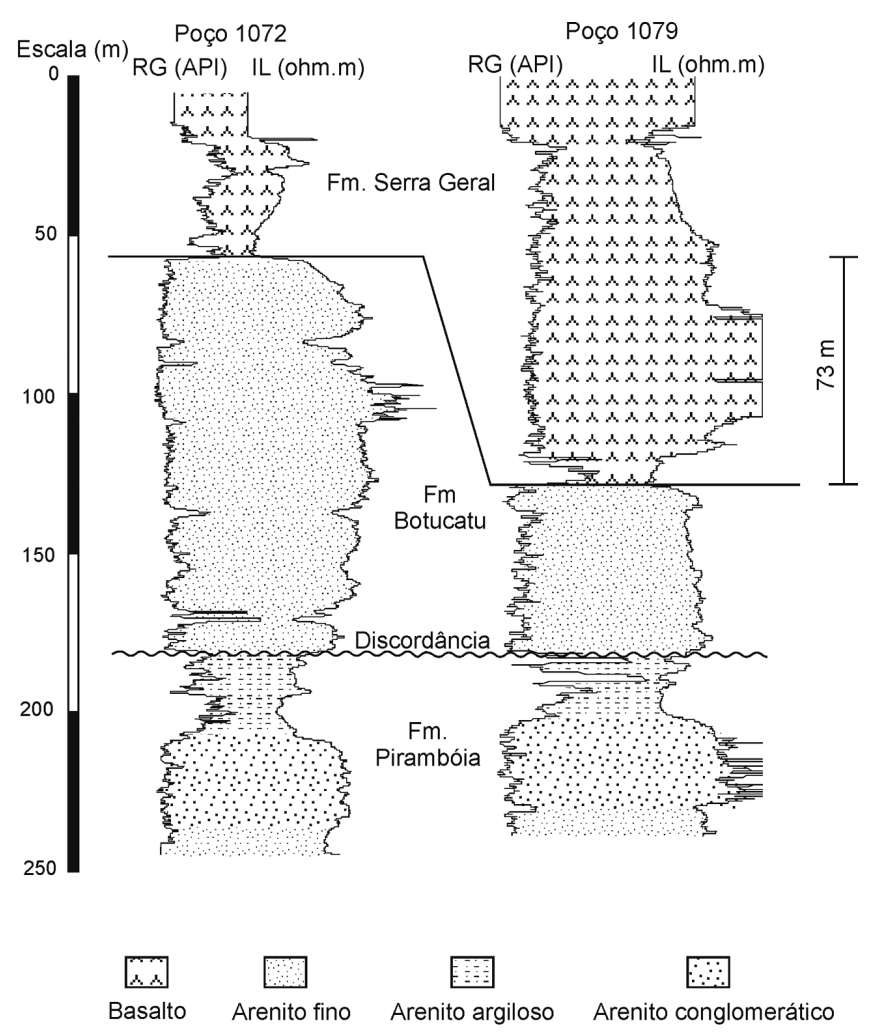

Contato concordante Contato discordante RG-Raios gama IL-Indução m

Figura 6 - Variação de espessura da Formação Botucatu em decorrência de processos eólicos atuantes em ambiente desértico.

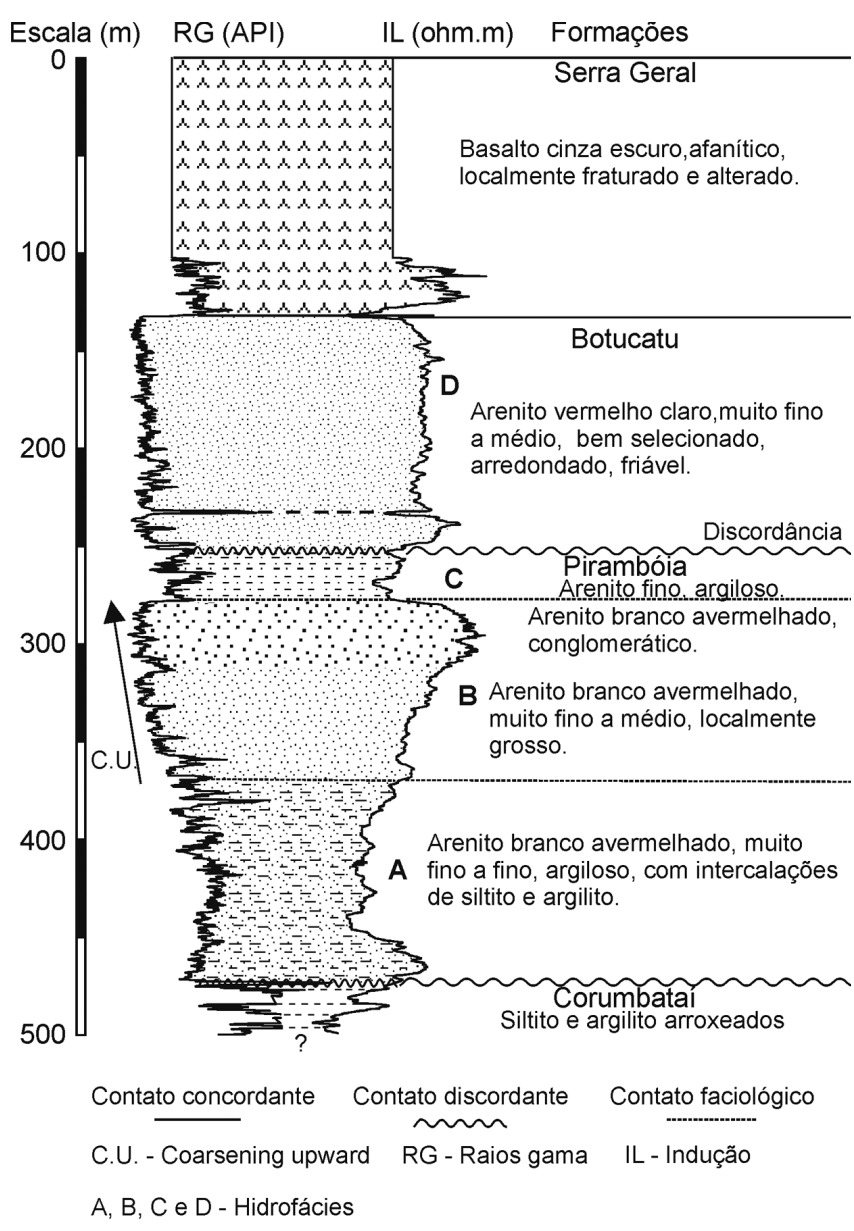

Figura 7 - Perfil hipotético da seqüência mesozóica da área urbana de Ribeirão Preto, elaborado com base em perfis geofisicos dos poços 1079, 1244 e 1020.

radioatividade em perfis (Formação Pirambóia), para arenitos com baixa radioatividade e pouco argilosos, acima (Formação Botucatu).

A configuração do contorno estrutural da discordância existente no topo da Formação Pirambóia (Fig. 9), na área de Ribeirão Preto, mostra uma superfície com caimento de nordeste para sudoeste que atinge desnível de mais de 100 metros em cerca de 15 $\mathrm{km}(6,7 \mathrm{~m} / \mathrm{km})$, formando uma depressão em forma de calha na extremidade inferior, cuja continuidade a sudoeste é ainda desconhecida por insuficiência de informações. A calha tem cotas inferiores a 350 metros em sua porção mais deprimida e a inclinação média de seus flancos dificilmente ultrapassa $3^{\circ}$. Mesmo não dispondo de perfis geofísicos, Sinelli (1970,1971a) já havia identificado uma área circular estruturalmente rebaixada, à qual denominou Depressão de Ribeirão Preto. Esta estrutura seria resultante da conjugação de movimentos tectônicos associados aos fenômenos magmáticos da Reativação Wealdeniana e da tectônica cenozóica.

ARCABOUÇO HIDROFACIOLÓGICO As seções geológicas das figuras 4 e 5 distinguem as hidro- 


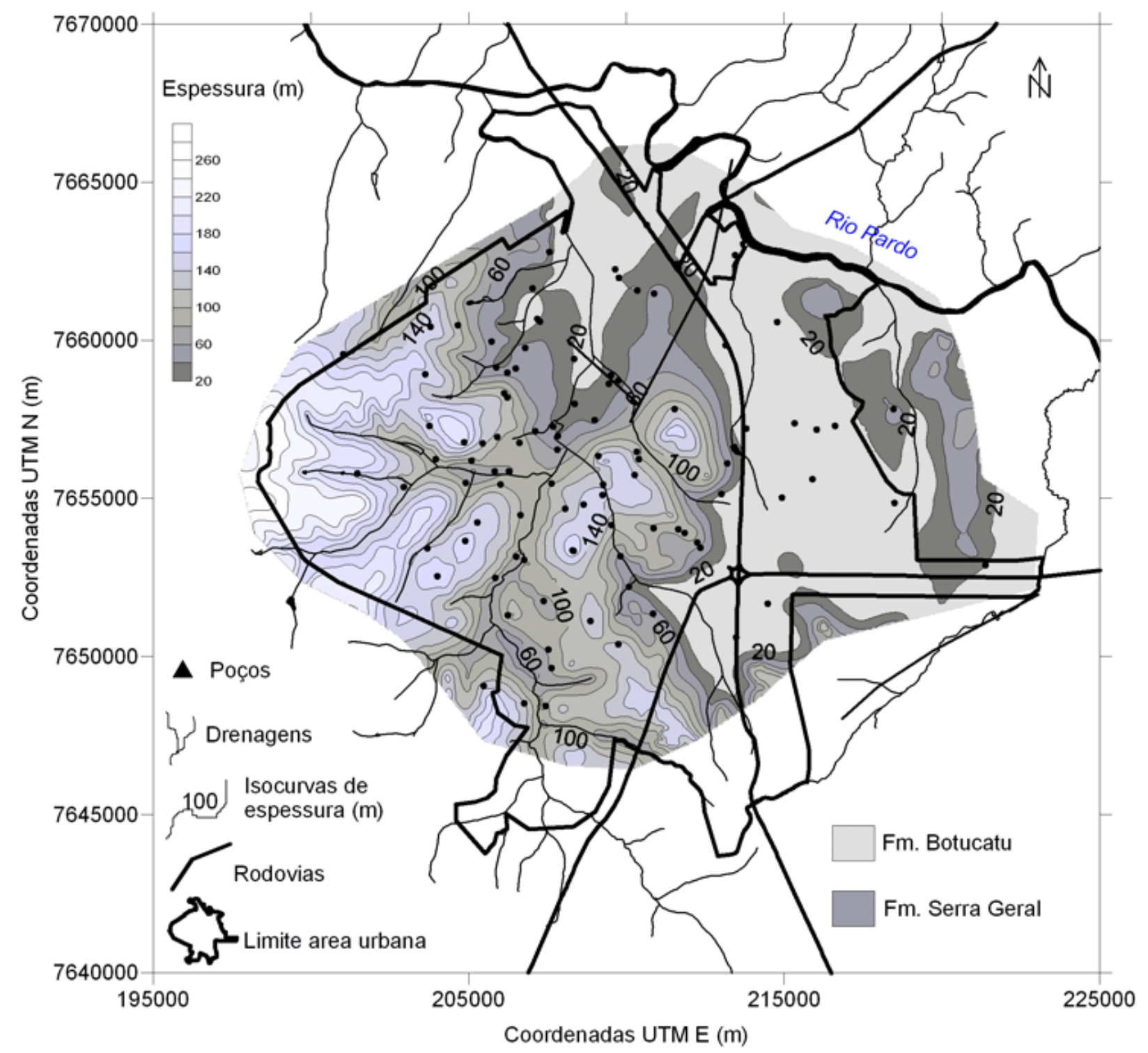

Figura 8 - Espessura da Formação Serra Geral na área urbana de Ribeirão Preto.

fácies componentes do Sistema Aqüífero Guarani , no município de Ribeirão Preto. Essas unidades hidroestratigráficas, de maior e de menor ordem, podem ser reconhecidas em todos perfis geofísicos de poços investigados, e correlacionadas consistentemente em toda área abrangida pelo estudo.

O Aqüífero Pirambóia pode ser desmembrado, da base para o topo, em 3 hidrofácies informalmente denominadas $\mathrm{A}, \mathrm{B}$ e $\mathrm{C}$, individualizadas por atributos geofísicos peculiares.

A hidrofácies A representa o intervalo inferior do Aqüífero Pirambóia na cidade de Ribeirão Preto. Suas características geofísicas, observadas em perfis de raios gama e de resistividade induzida, apontam sedimentos arenosos finos, com elevado conteúdo de argila que, por sua vez, confere redução da condutividade hidráulica do pacote, enquadrando-o na categoria de aqǘfero pobre. $\mathrm{Na}$ área, a espessura máxima alcançada por esta hidrofácies, com base nos perfis cadastrados, foi de 106 metros no poço 1020 (Fig. 4). Em geral, esta hidrofácies não é penetrada integralmente pelos poços construídos na cidade de Ribeirão Preto, fato que impede a verificação da variação de espessura da hidrofácies lateralmente, e a análise do comportamento tectônico do topo estrutural do substrato do SAG, constituído pela Formação Corumbataí. Freqüentes intrusões de diabásio em níveis aleatórios, comuns nesta hidrofácies, constituem barreiras ao fluxo subterrâneo.

A hidrofácies B compõe uma sucessão com espessura média de 80 metros, formada por corpos arenosos de granulometria crescente da base para o topo e diminuição da argilosidade no mesmo sentido, configurando um perfil granulométrico em padrão coarsening upward, característico desta porção do Aqüífero Pirambóia na cidade de Ribeirão Preto. Em geral, a porção inferior da hidrofácies B é representada por arenitos vermelho-acastanhados, finos a médios, relativamente mais argilosos e pouco espessos (poucos metros), que gradam a arenitos 


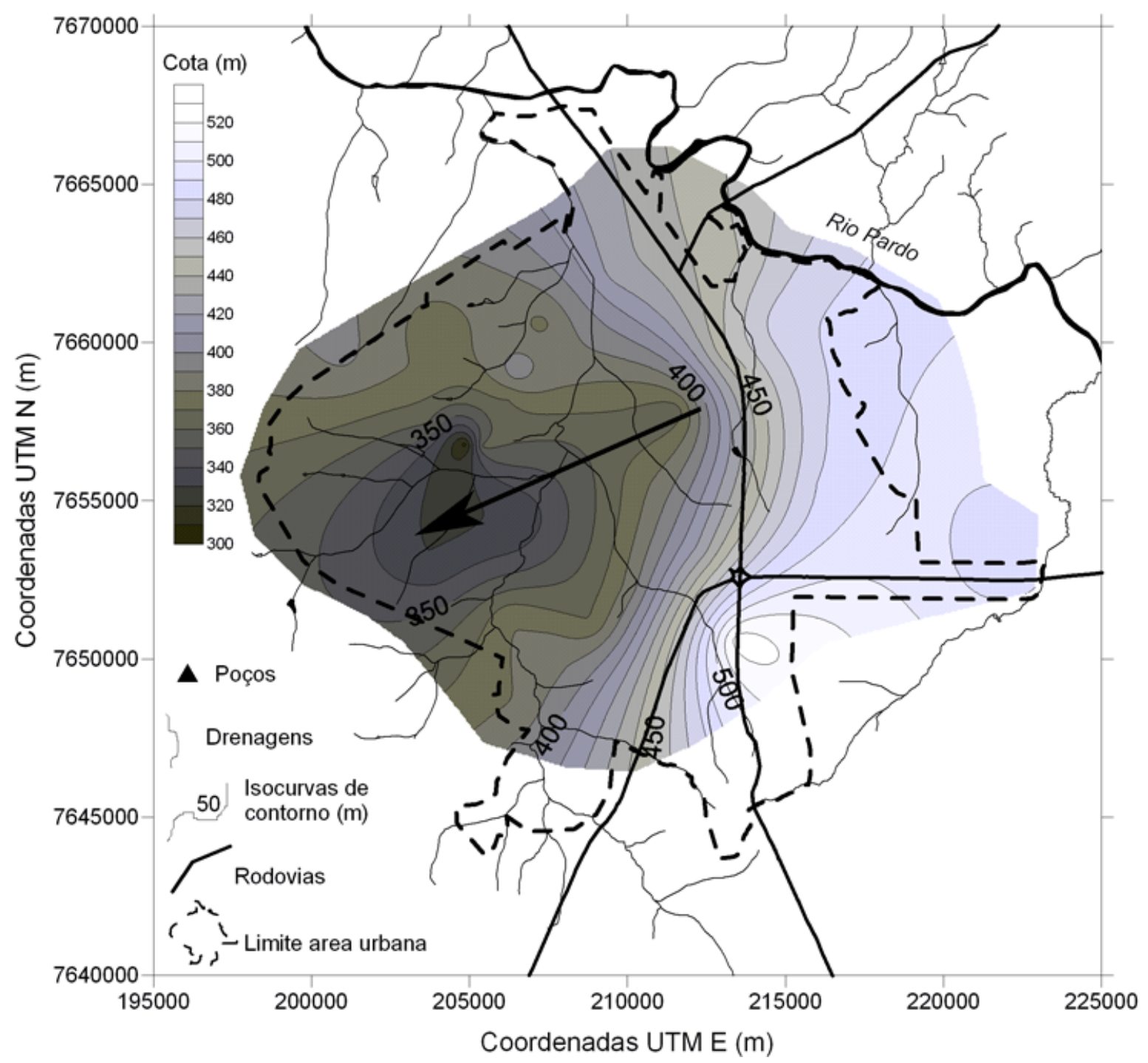

Figura 9 - Contorno estrutural do topo da Formação Pirambóia (Seta indica direção do mergulho estrutural).

limpos, em geral dominantes nesta hidrofácies; a porção superior da hidrofácies é representada por arenitos acastanhados, finos a grossos, em parte conglomeráticos, em geral com espessuras variando entre 20 e 40 metros, podendo ocasionalmente atingir mais de 120 metros, como observado no perfil do poço 1086 (Fig. 4).

Esta notável variação faciológica salienta a complexidade hidroestratigráfica do Aqüífero Pirambóia, cujas características geofísicas, reveladas em perfis de raios gama e de resistividade induzida, indicam seção portadora de reservatórios com boas características de permoporosidade, principalmente em sua porção médio-superior.

O padrão granulométrico da porção superior da hidrofácies $\mathrm{B}$, observado em perfis geofísicos, aliado às características litológicas descritas em amostras de calha de poços, sugere dominância de deposição por rios entrelaçados. Esta interpretação paleoambiental é corroborada por Assine \& Soares (1995), Caetano-Chang (1997) e Caetano-Chang \& Wu (2006), para sedimen- tos com características similares observados na porção médio-superior da Formação Pirambóia, em outros pontos da bacia.

O intervalo hidroestratigráfico superior do Aqüífero Pirambóia, em Ribeirão Preto, é representado pela hidrofácies $\mathrm{C}$, que se assenta sobre arenitos conglomeráticos da hidrofácies B. A hidrofácies C, composta por arenitos finos a muito finos, argilosos, com características geofísicas indicativas de baixa permoporosidade, separa as hidrofácies do Aqüífero Pirambóia da hidrofácies $\mathrm{D}$, sobrejacente, representada pelo Aqüífero Botucatu, dificultando, assim, a interconectividade hidráulica entre os reservatórios abaixo e acima deste intervalo. A espessura máxima da hidrofácies $\mathrm{C}$, registrada neste estudo, foi de 32 metros no poço 1086 (Fig. 4).

Com base nos perfis geofísicos disponíveis nesta pesquisa, a espessura máxima constatada do Aqüífero Pirambóia, na área estudada, foi de 250 metros no poço 1086, sem que a perfuração tivesse atingido o topo da 
Formação Corumbataí.

Embora variações litológicas também sejam observadas ao longo do perfil estratigráfico do Aqüífero Botucatu, estas não inspiram subdivisões, em razão da pequena diferença de comportamento hidrodinâmico sugerido pelos perfis geofísicos e pela textura desses sedimentos, descritos como constituídos por arenitos finos a médios, arredondados, friáveis, com baixo conteúdo argiloso. Estas características sugerem reservatórios de elevada permoporosidade, originados por processos predominantemente eólicos, que podem ser avaliados como bons aqǘferos. Em geral, na base da hidrofácies D aparecem sedimentos com maior percentual de areia grossa, que marcam bruscamente o início da sucessão Botucatu.

A espessura máxima do Aqüífero Botucatu, observada em Ribeirão Preto, foi de 122 metros no poço 1072 (Fig. 6).

CONCLUSÕES O município de Ribeirão Preto tem seu abastecimento de água suprido integralmente por cerca de 100 poços públicos que captam água do Sistema Aqüífero Guarani. Esses poços, no entanto, não foram projetados para alcançar o substrato impermeável do SAG (Formação Corumbataí), deixando assim de fornecer importantes informações litofaciológicas, estratigráficas, estruturais e tectônicas, essenciais para o entendimento do comportamento hidrogeológico e para a gestão deste complexo manancial subterrâneo. Apesar da incompletude das informações, foi possível, com base principalmente na interpretação de perfis geofísicos de poços, delinear o arcabouço estratigráfico-estrutural do Sistema Aqüífero Guarani e identificar suas principais hidrofácies.

O arcabouço litoestratigráfico do Sistema Aqüífero Guarani, em Ribeirão Preto, é composto pelas formações Pirambóia e Botucatu que, individualmente, compõem unidades aqüíferas homônimas. Este pacote rochoso assenta-se sobre substrato impermeável, formado por rochas pelíticas da Formação Corumbataí, cujo comportamento hidrodinâmico regional é de um aqüiclude, e é recoberto extensivamente por rochas basálticas da Formação Serra Geral, ausentes apenas em parte das porções leste e nordeste da área urbana, onde estão expostos sedimentos da Formação Botucatu.

A Formação Pirambóia alcançou espessura de 250 metros em poço que não penetrou toda sua extensão. Como praticamente todos os poços perfurados em Ribeirão Preto não atravessaram integralmente esta unidade, sua variação de espessura não pôde ser avaliada. Já a espessura da Formação Botucatu é bastante variável de- vido, em grande parte, à preservação do relevo de dunas pelas lavas que cobriram a unidade e às depressões resultantes de erosão eólica pronunciada. Variações faciológicas nestas duas unidades foram bem salientadas pelos perfis geofísicos, denotando a complexidade hidroestratigráfica do SAG no município de Ribeirão Preto.

A discordância que separa as formações Pirambóia e Botucatu constitui excelente marco local para correlações estratigráficas e análises estruturais. $\mathrm{O}$ exame do mapa de contorno estrutural dessa discordância evidenciou a existência de uma depressão, com caimento para sudoeste e cotas inferiores a 350 metros nas porções mais deprimidas, identificada em trabalhos anteriores como Depressão de Ribeirão Preto, que teria origem devido a movimentações tectônicas associadas aos fenômenos magmáticos da Reativação Wealdeniana e à tectônica cenozóica. A inexistência de dados de topo da Formação Corumbataí não permite análise consistente sobre a magnitude dos processos tectônicos que afetaram as unidades constituintes do SAG, ainda que movimentos verticais possam ser deduzidos localmente.

O Aqüífero Pirambóia é composto por três hidrofácies; as hidrofácies A, inferior, e C, superior, apresentam características de permoporosidade reduzida, em virtude de maior conteúdo de argila; a hidrofácies B, mediana e em geral mais espessa, é composta por arenitos finos a grossos, em parte conglomeráticos, com elevada permoporosidade. O Aqǘf́re Botucatu, formado unicamente pela hidrofácies $\mathrm{D}$, é composto por arenitos finos a médios, limpos, de elevada permoporosidade.

Somente a exigência de requisitos técnicos específicos, quando da construção de poços tubulares profundos de grande vazão, por parte de órgãos gestores de recursos hídricos, permitirá o melhor conhecimento hidrogeológico de Ribeirão Preto, e poderá garantir a implantação de modelo de gestão de recursos hídricos subterrâneos em harmonia com as políticas ambientais e de saneamento do município.

Agradecimentos Os autores agradecem ao Laboratório de Estudo de Bacias - LEBAC, da Universidade Estadual Paulista "Júlio de Mesquita Filho", Campus de Rio Claro, pelo suporte técnico e financeiro para elaboração deste artigo, e aos geólogos José Laércio Sanches, do Departamento de Aguas e Energia Elétrica do Estado de São Paulo, Maurício de Melo Figueiredo Jr., da Secretaria de Planejamento e Gestão Ambiental de Ribeirão Preto, e João Paulo Fonseca Correia, do Departamento de Água e Esgoto de Ribeirão Preto (DAERP), pelas informações técnicas disponibilizadas.

\section{Referências}

Almeida F.F.M. 1953. Botucatu: a triassic desert of South America. In: IUGS, International Geological Congress, 19, Argel (Argélia), Comptes Rendus, section 19, fasc. 7, p. 9-24.

Assine M.L. 1993. O eólico e o fluvial na Formação Piram- bóia. In: SBG, Simpósio Sul-Brasileiro de Geologia, 5, Curitiba, Resumos, p. 53-54.

Assine M.L \& Soares P.C. 1995. Interação flúvio-eólica na Formação Pirambóia. In: SBG, Simpósio de Geologia do Sudeste, 4, Águas de São Pedro, Boletim de resumos 
expandidos, p.65.

Assine M.L., Piranha J.M., Carneiro C.D.R. 2004. Os paleodesertos Pirambóia e Botucatu. In: Mantesso Neto V., Bartorelli A., Carneiro C. D. R., Brito Neves B.B. (org.). Geologia do continente sul-americano: evolução da obra de Fernando Flávio Marques de Almeida. São Paulo, Beca, p. 77-92.

Caetano-Chang M.R. 1997. A Formação Pirambóia no centro-leste do Estado de São Paulo. Tese de Livre Docência, Instituto de Geociências e Ciências Exatas, Universidade Estadual Paulista (UNESP), Rio Claro, 196 p.

Caetano-Chang M.R. \& Wu F.T. 1993. A composição faciológica das formações Pirambóia e Botucatu no centro-leste paulista e a delimitação do contato entre as unidades. In: Simpósio sobre Cronoestratigrafia da Bacia do Paraná, 1, Rio Claro, Boletim de resumos expandidos, p. 93.

Caetano-Chang M. R. \&.Wu F.T. 2006. Arenitos flúvioeólicos da porção superior da Formação Pirambóia no centro-leste paulista. Revista Brasileira de Geociencias, 36 (no prelo).

DEPARTAMENTO DE ÁGUAS E ENERGIA ELÉTRICA (DAEE). 1974. Estudo de águas subterrâneas, Região Administrativa 6, Ribeirão Preto. São Paulo. 2 v.

DEPARTAMENTO DE ÁGUAS E ENERGIA ELÉTRICA (DAEE). 1990. Plano estadual de recursos hídricos: Primeiro plano do estado. Síntese. São Paulo. 97 p.

DEPARTAMENTO DE ÁGUA E ESGOTO DE RIBEIRÃO PRETO DAERP. 2007. Abastecimento de Água em Ribeirão Preto. Disponível em: http://www.daerp.ribeiraopreto.sp.gov.br, acesso em 15/02/2007.

Davino A., Sinelli O., Souza A. 1980. Gravimetria, sondagem elétrica e perfilagens geofísicas: pesquisa de água subterrânea em Ribeirão Preto (SP). In: SBG, Congresso Brasileiro de Geologia, 31, Santa Catarina, Anais, v.2, p. 904-914.

Machado J.L.F. \& Faccini U.F. 2004. Influência dos falhamentos regionais na estruturação do Sistema Aqüífero Guarani no Estado do Rio Grande do Sul. In: ABAS, Congresso Brasileiro de Águas Subterrâneas, 13, Cuiabá, Anais CD-ROM, p. 1-14.

Milani E.J. 1997. Evolução Tectono-Estratigráfica da Bacia do Paraná e seu relacionamento com a Geodinâmica Fanerozóica do Gondwana Sul-Ocidental. Tese de Doutorado, Universidade Federal do Rio Grande do Sul (UFRGS), Porto Alegre. V.1 texto. V.2 Anexos.

Milani E.J., França A.B., Schneider R.L. 1994. Bacia do Paraná. Boletim de Geociencias da Petrobrás, 8:69-82.

Paula e Silva F. 1988. Exploração do Sistema Aqüífero Botucatu na cidade de Bauru - SP: o condicionamento tectônico na avaliação do potencial hídrico da área. In: ABAS, Congresso Brasileiro de Águas Subterrâneas, 5, São Paulo. Anais, p. 12-20.

Paula e Silva F \& Cavaguti N. 1994. Nova caracterização estratigráfica e tectônica do Mesozóico na Cidade de Bauru - SP. Revista Geociências, 13(1):83-99.

Peate D.W., Hawkesworth C.J., Mantovani M.S.M. 1992. Chemical stratigraphy of the Paraná lavas, South America: classification of magma types and their spatial distribution. Bulletin of Volcanology, 55:119-139.

Sinelli O. 1970. Água subterrânea no Municipio de Ribeirão
Preto e adjacências (SP). Tese de doutoramento, Faculdade de Filosofia, Ciências e Letras de Ribeirão Preto, Universidade de São Paulo (USP), Ribeirão Preto, 213 p.

Sinelli O. 1971a. Geologia e Água Subterrânea no Município de Ribeirão Preto. In: SBG, Congresso Brasileiro de Geologia, 25, São Paulo, Anais, v.2, p.14-34.

Sinelli O. 1971b. Considerações gerais sobre a tectônica no Município de Ribeirão Preto, SP. In: SBG, Congresso Brasileiro de Geologia, 25, São Paulo, Anais, v.2, p.145-151.

Sinelli O. 1984. Análise do nível piezométrico nos últimos 50 anos no município de Ribeirão Preto, SP. In: ABAS, Congresso Brasileiro de Águas Subterrâneas, 3, Fortaleza, Anais. p. 450-464.

Sinelli O., Davino A., Souza A., Gonçalves N.M.M., Teixeira J. 1980. Hidrogeologia da região de Ribeirão Preto (SP). In: ABAS, Congresso Brasileiro de Águas Subterrâneas, 1, Recife, Anais, p. 319-335.

Sinelli O., Souza A., Davino A., Sanches J.L. 1984. As intrusivas básicas e suas implicações na prospecção das águas subterrâneas. In: ABAS, Congresso Brasileiro de Águas Subterrâneas, 3, Fortaleza, Anais, v.2, p.441-449.

Soares P.C. 1974. Elementos estruturais da parte nordeste da Bacia do Paraná: classificação e gênese. In: SBG, Congresso Brasileiro Geologia, 28, Porto Alegre, Anais, v.4, p.107-121.

Soares P.C. 1975. Divisão estratigráfica do Mesozóico no Estado de São Paulo. Revista Brasileira de Geociências, 5:229-251.

Soares P.C. 1981. Estratigrafia das formações jurássico-cretáceas na Bacia do Paraná - Brasil. In: Volkheimer W. \& Musacchio E.A. (eds.) Cuencas Sedimentarias del Jurássico y Cretácico de America del Sur, Buenos Aires, vol.1, p. 275-304.

Soares P.C., Sinelli O., Penalva F., Wernick E., Souza A., Castro P.R.M. 1973. Geologia do nordeste do Estado de São Paulo. In: SBG, Congresso Brasileiro de Geologia, 27, Aracaju, Anais, v.1, p. 209-236.

Strugale M., Rostirolla S.P., Rosa Filho E.F., Hindi E.C., Mancini F., Ferreira J.F.F., Freitas R.C. 2002. Arcabouço estrutural do Arco de Ponta Grossa na região centro-norte do Estado do Paraná (Brasil): Implicações na hidrodinâmica do Sistema Aqüífero Guarani. In: ABAS, Congresso Brasileiro de Águas Subterrâneas, 12, Florianópolis, Anais CD-ROM, p. 1-19.

Suguio K., Fulfaro V. J., Amaral G., Guidorzi L.A. 1977. Comportamentos estratigráfico e estrutural da Formação Bauru nas regiões administrativas 7 (Bauru), 8 (São José do Rio Preto) e 9 (Araçatuba) no Estado de São Paulo. In: SBG, Simpósio Regional de Geologia, 1, São Paulo, Atas, p. 231-247.

Zalán P.V., Wolff S., Conceição J.C.J. 1987. Tectônica e sedimentação da Bacia Sedimentar do Paraná. In: SBG, Simpósio Sul-Brasileiro de Geologia, 3, Curitiba, Atas, v.1, p.441-474.

Manuscrito ID 8220 Submetido em 26 de junho de 2007 Aceito em 06 de junho de 2008 Sistema eletrônico de submissão 